\title{
Well-to-Wheel analysis of natural gas for hybrid electric truck application
}

\author{
F. Zhang ${ }^{1}$, W.B. Nader ${ }^{2}$,A. Zoughaib ${ }^{3}$, X. Luo ${ }^{4}$ \\ ${ }^{I}$ China-EU Institute for Clean and Renewable Energy, Huazhong University of Science and \\ Technology, Wuhan, China \\ ${ }^{2}$ École des Mines, Paris, France \\ ${ }^{3}$ École des Mines, Paris, France \\ ${ }^{4}$ State Key Laboratory of Coal Combustion, School of Energy and Power Engineering, Huazhong \\ University of Science and Technology, Wuhan, China
}

\begin{abstract}
Compressed natural gas as an alternative fuel obviously has a great potential to reduce the greenhouse gas emissions. Although several studies on the life cycle are quite comprehensive for passenger vehicles, it is problematic to apply these results to heavy-duty electric hybrid trucks. This paper describes the Well-to-Wheel methodology for environmental impact from the gas production to its final application. The $\mathrm{CO} 2$ equivalent emissions and the methane leakage point will be identified at the end. The results indicate that compressed natural gas-based trucks have $18.7 \%$ less $\mathrm{CO} 2$ equivalent emissions than diesel-based ones. However, this benefit may be affected by methane leakage, particularly, in the recovery phase. Reducing methane emissions upstream could be an opportunity to optimize the pollution performance of heavy hybrid electric trucks.
\end{abstract}

\section{Introduction}

The energy industry is in a critical period of transformation due to energy shortages and pressing environmental concerns. Greenhouse gas (GHG) emissions are considered to be the main cause of the temperature increase and global climate change. $\mathrm{CO} 2, \mathrm{CH} 4$, and $\mathrm{N} 2 \mathrm{O}$ are the main GHGs resulting from power generation and fuel combustion [11]. The global average volume of $\mathrm{CO} 2$ reached a new record height at 407.4 parts per million in 2018, which seemed like an almost instantaneous rise in geological time scale [14].

Due to the pressing environmental concerns, more attention has been paid to GHG emissions following global and foreign regulatory strategies, including new regulations on automotive GHG limits [7]. In 2017, GHG pollution from the road transport industry in the USA attained $28.2 \%$ [12]. Passenger vehicles accounted for $41.0 \%$ of main retail outlets, freight trucks for $23.2 \%$, and light-duty truck for $17.5 \%$ [1]. About $30 \%$ of $\mathrm{CO} 2$ emissions from heavy-duty vehicles (HDV) will continually increase to $40 \%$ by 2030 if no effective action is introduced [2]. Nahlik et al. reported that HD trucks accounted for $99 \%$ of California's emissions from intra-state good transportations [16]. Based on these studies, alternative fuel productions and technology innovations are essential for the fuel industry and truck manufacturing, as they can help achieving a significant reduction in GHG emissions afterward. 
Compared to petroleum and diesel, the low-cost and less emission benefits of natural gas (NG) attract a lot of attention [6,9]. It has a clear advantage of being used as an alternative fuel in primary energy consumption $[15,18]$. It is used mainly in the form of compressed natural gas $(\mathrm{CNG})$ or liquefied natural gas (LNG) in the car industry. Generally, the CNG is used in passenger and light freight, road buses, and public-use vehicles. LNG uses comprises line-cars, rail and water-borne transport, and agricultural machinery. Although only $1 \%$ of HDVs were natural gas-based, the demand for this fuel still has a huge development potential in this segment [17]. The expansion of heavy-goods vehicles will bring the continued growth of the LNG and CNG demand according to the EIA's 2018 Annual Energy Outlook forecast [4, 5].

With the electrification of transportation, hybrid electric trucks will be widely used in future to comply with the city carbon emission regulations. Applying natural gas for hybrid electric trucks may lead toa great reduction in GHGs emissions. However, most CNG trucks have lower efficiency in combustion and higher levels of methane slip. If the upstream methane emissions are also considered, these trucks may also contribute to global warming. One of the reasons for this doubt is the methane emissions caused during production and utilization. The issue would become serious with the current boom in NG production and consumption.

The Well-to-Wheel (WtW) analysis is an important way to measure the effect of fuel sand is commonly used today in environmental assessment and policy decisions. Based on our study of the literature, most of the $\mathrm{WtW}$ studies have mainly focused on passenger vehicles. Although natural gas used in passenger vehicles has the potential to emit less GHGs, the emission reduction opportunity on this part is small, because for passenger vehicles, it would take a long time to fully transfer to the hybrid or electric fuels, and compared with heavy-duty trucks the effect of emission reduction will be lower. And for hybrid electric trucks with a high potential of reduction, there is no comprehensive WtW assessment. Furthermore, the specific points of leakage at the various stages are not illustrated in detail.

Based on the previous points, these limitations can be addressed in this study, and an independent emission estimation method will be provided to assess the GHG emission reduction potential for CNG-based hybrid electric trucks.

\section{Methodology}

Throughout the life cycle of NGVs, CO2 emissions arise not only from fuel combustion, but also from the production and distribution of fuel. In order to make the research more understandable, WtW analysis is always divided into upstream (Well-to-Tank) and downstream (Tank-to-Wheel), i.e., from a gas well to the gas combustion in an engine. The Well-to-Tank (WtT) covers the stages of recovery, refining, compression or liquefaction, transmission, and delivery pathways [8]. The Tank-to-Wheel (TtW) considers only the energy use and $\mathrm{CO} 2$ equivalent emissions from the trucks. In this paper, the WtT results are combined with the TtW results to provide comprehensive $\mathrm{WtW}$ results for the lifecycle of CNG use in hybrid electric trucks.

The data for this study are mostly taken from IEA, EPA, EIA, GREET model and other literatures, and the other data are educated guesses based on a large research. The results are compared with conventional diesel trucks, since diesel is the primary fuel in HDVs. 


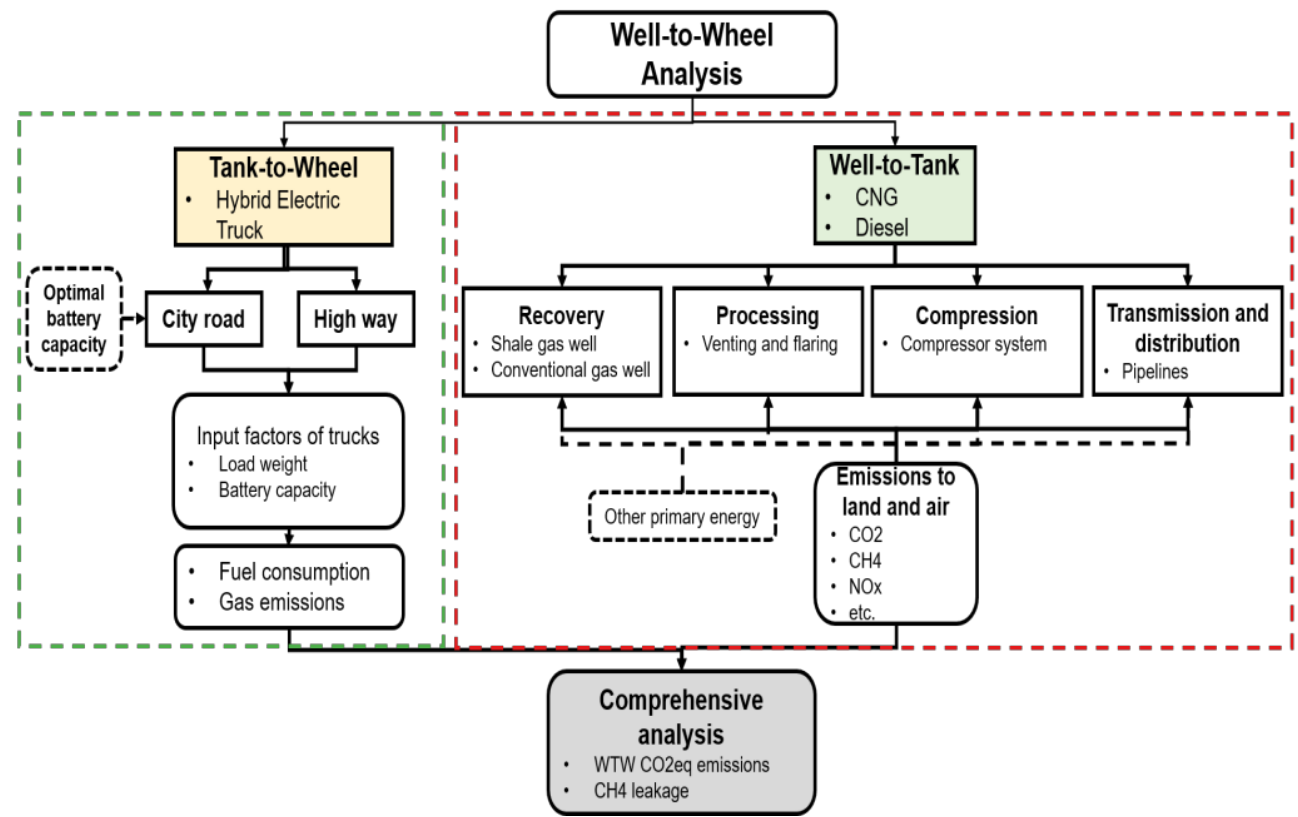

Fig. 1. Methodology of Well-to-Wheel analysis.

For clarity, emissions of CNG over the whole life cycle will be estimated separately in different parts. Leaks and $\mathrm{CO} 2$ emissions from the upstream are presented in Section 3. The leak that occurred during the WtT process will be covered in detail in this section. Emission estimates for hybrid electric trucks are presented in Section 4. The results will be integrated into Section 5 to import a comprehensive evaluation for the entire process. The WtW database would support the transportation electrification, which will be necessary to meet increasingly strict pollution standards.

\section{Well-to-tank analysis}

The WtT process includes emissions associated with the production, processing, com-press ion, as well as transportation and distribution of gas. This cycle begins at the point of use of raw materials, to where the fuel is transported for energy consumption. The overall process flow is shown in Figure 2.

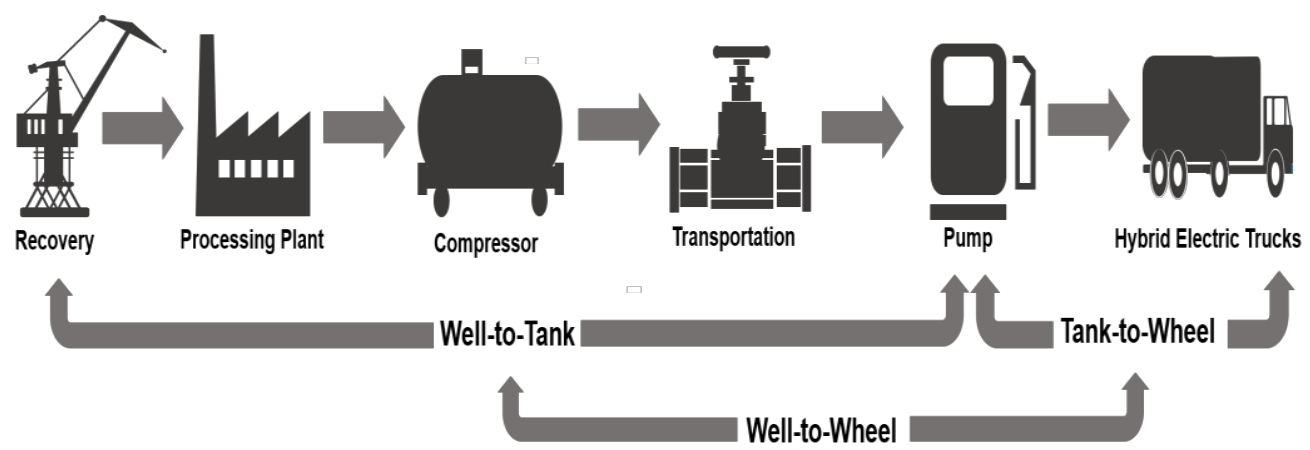

Fig. 2. System boundary of Well-to-Wheel analysis. 
During production, natural gas and oil will be first separated. It will then be sent to a processing plant for pre-treatment, which will include some venting and flaring of natural gas. After that, the NG will be sent to various stations for compression. Finally, the CNG will be transported and stored in a tank. This whole process is defined as WtT. Only the $\mathrm{CO} 2$ equivalent emissions from this process are calculated in this part, including the usage of primary energy, methane leakage, emissions from transportation, etc.

During the recovery process, tiny portions of the crude CNG are regularly used as fuel, vented, burned, or unintentionally released into the environment for conducting experiments, repair or maintenance. This is one source of methane emissions at this stage. Besides, combustion of fuel or other auxiliary energy also results $\mathrm{CH} 4$ emissions. Upon processing, NG and shale gas must be refined before being used as commercial fuels. This takes place immediately after production to separate water, oil, higher hydrocarbon, and other impurities and increase the methane content from $78.3 \%$ to $92.8 \%$ [13].

After processing, the NG will be pumped directly into a compressor station and compressed to 276 bar to compensate for the pressure drops that will occur as a result of refrigeration while the trucks are being loaded into the tanker to a pressure of 248 bar. The compressor efficiency ranges from $91.7 \%$ to $98 \%$; for this study it is taken constant at $95 \%$. During this process, the electricity produced by the feedstock and fuel combustion is the main source of power for the compressors. Processed natural gas is often distributed during the transmission in long-distance pipelines. The pressure for feeding NG to the pipeline will decrease with the age of the gas fields. So the additional gas turbine-driven compressors are required in this stage. In this study, the lifetime of pipelines is assumed at 50 years. The compression energy needed for this long-range transport distance implies higher expended energy and GHG emissions.

Table 1. Global warming potentials of greenhouse gases: relative to $\mathrm{CO} 2$.

\begin{tabular}{lc}
\hline Type & AR5/GWP \\
\hline Time horizon (YR) & 100 \\
$\mathrm{CO} 2$ & 1 \\
$\mathrm{CH} 4$ & 30 \\
$\mathrm{~N} 2 \mathrm{O}$ & 265
\end{tabular}

For the study of the $\mathrm{CO} 2$ emission sources, $\mathrm{CO} 2$ equivalent emissions are introduced as a standard, which is calculated based on the Global-warming potential (GWP) values. The $\mathrm{CO} 2$ equivalent emissions of methane are equal to the quantity (in kilograms) of emitted methane multiplied by theme thane GWP factor. On a 100-year basis, methane emissions are 30 times more potent than $\mathrm{CO} 2$ emissions.

If this effect is converted to $\mathrm{CO} 2$ equivalents, then the total $\mathrm{CO} 2$ equivalents produced in the entire WtT process can be obtained. The detailed emissions in each stage are shown in Figure 3, and the cumulative uncertainties of each pathway are shown by error bars. 


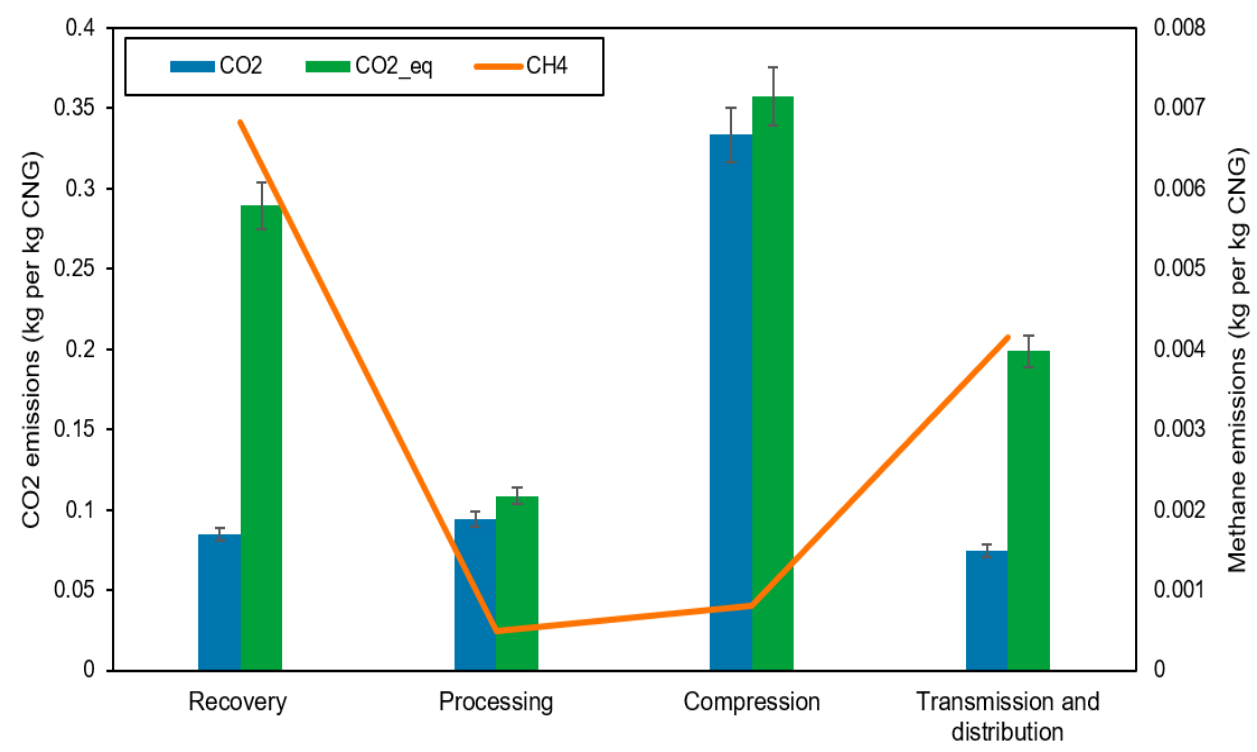

Fig. 3. Well-to-Tank CO2 equivalent emissions per kg CNG production in each stage.

$\mathrm{CO} 2$ is mainly emitted during compression, higher than that of the recovery process. If the GHG effect factor is taken into consideration, the results will be totally different. $\mathrm{CO} 2$ equivalent emissions in the recovery process increase sharply with the increase of $\mathrm{CH} 4$ emissions. Similarly, emissions of $\mathrm{CH} 4$ cause an increase in $\mathrm{CO} 2$ eq in the transmission and distribution stages. Improving energy efficiency in the recovery process will soon be the crucial method for reducing $\mathrm{CO} 2$ emissions. Furthermore, the long average distance between the well and the filling station also results in bigger energy consumption and emissions.

Figure 4 describes the amount of methane emissions in different stages. 55.3\% methane emissions are coming from the recovery process and most parts of the emissions are leaks, accounting for $93.9 \%$. The second largest methane emissions part is the transmission and distribution stages. 


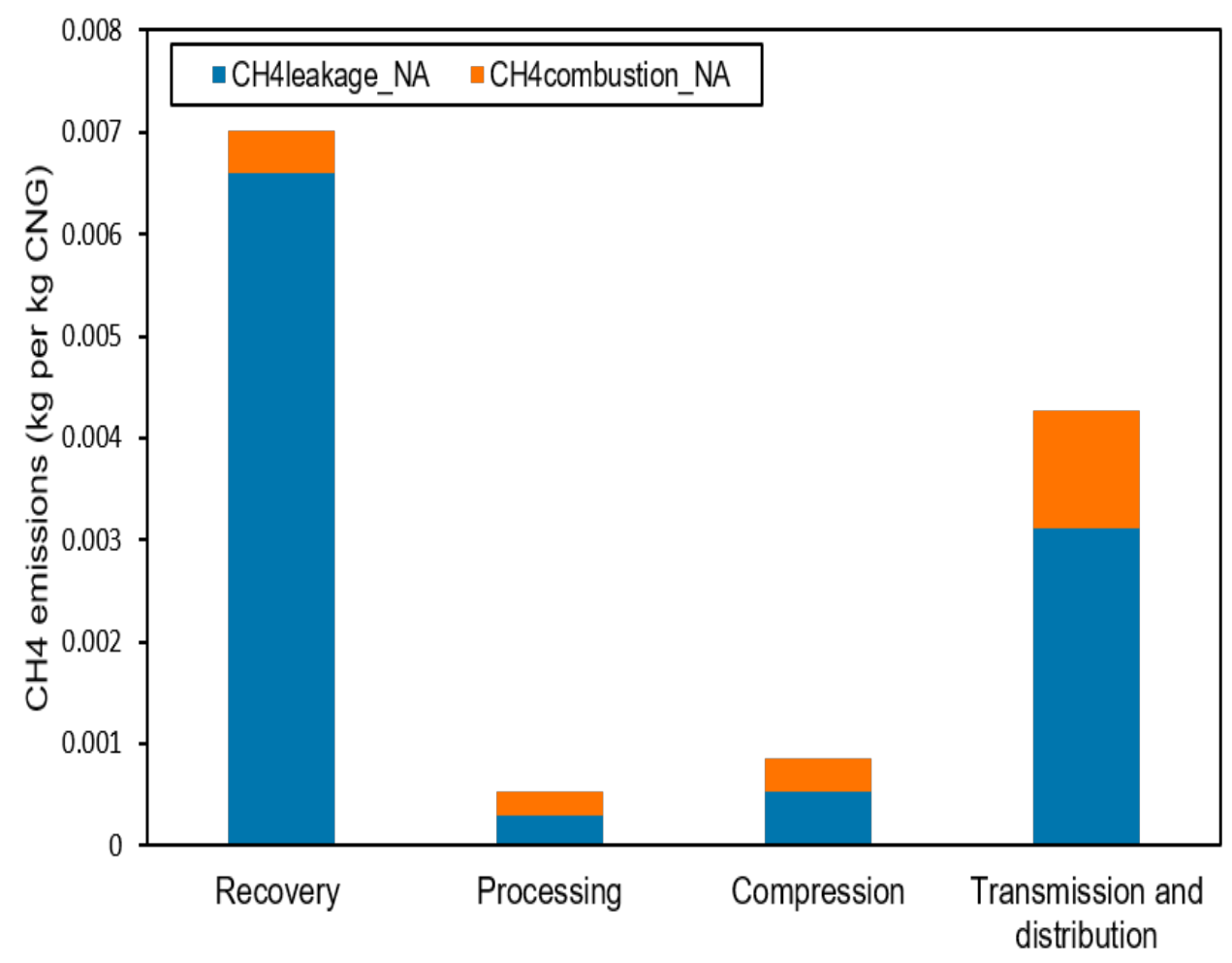

Fig. 4. Well-to-Tank CH4 emissions of each stage in North America.

The methane emissions consist of two parts: fuel combustion and leakage. The emissions from combustion are mostly caused by primary energy utilization. The leakage emissions are caused by many reasons. The well equipment contributes the largest part of the venting and leakage, accounting for $96.8 \%$, mainly from the pneumatic controller and other types of equipment. This part has a great potential to be reduced with good control. Besides, liquid unloading is the main $\mathrm{CH} 4$ leakage source for both conventional and unconventional wells. For compressor systems, the lower compressor efficiency results in larger amounts of $\mathrm{CO} 2$ emissions. The main causes include compressor vents, leaky valves, exhaust engine reciprocating, and other equipment. Other sources of $\mathrm{CH} 4$ pollution are safety valves, block valves, pipeline connectors, and other measurement devices [12] in the transportation process. The methane leakage is estimated at $0.13 \%$ per $1000 \mathrm{~km}$ of transported gas [3]. And the possibility of leakage increases with the increase of distribution distances.

\section{Tank-to-wheel analysis}

The model is established on the basis of a virtual hybrid electric truck of a characteristic commercial type in nowadays market. This model is used as an instrument for comparing different running scenes. In order to make a clear comparison between diesel-based trucks, fuel consumption and $\mathrm{CO} 2$ emissions are considered in numbers of kilograms per 100 kilometers. Basic truck characteristics and technologies considered in this study are given in Table 2 with quite a reasonable assumption.

Table 2. Parameters of the hybrid electric truck. 


\begin{tabular}{lll} 
Parameters & Unit & Value \\
\hline Trailer load & $\mathrm{kg}$ & $1000-25000$ \\
Truck weight & $\mathrm{kg}$ & 12551 \\
Fuel weight & $\mathrm{kg}$ & 200 \\
Battery weight & $\mathrm{kg}$ & 2210 \\
Battery capacity & $\mathrm{kwh}$ & 160 \\
Engine efficiency & $\%$ & 45 \\
Transmission efficiency & $\%$ & 97 \\
Generator power & $\mathrm{kw}$ & 250 \\
Max engine efficiency & $\%$ & 45 \\
Highway distance & $\mathrm{km}$ & 300 \\
City road distance & $\mathrm{km}$ & 24 \\
& & \\
\hline
\end{tabular}

The configuration of the hybrid electric model is presented in Figure 5. The parallel hybrid truck has an electric motor directly connected to the transmission. The ICE drives the electric machine (EM) to recharge the battery. During city driving, the clutch will be activated and the battery will provide the required power to the EM. Consequently, this architecture offers a lower engine power while maintaining good performance in all driving conditions.

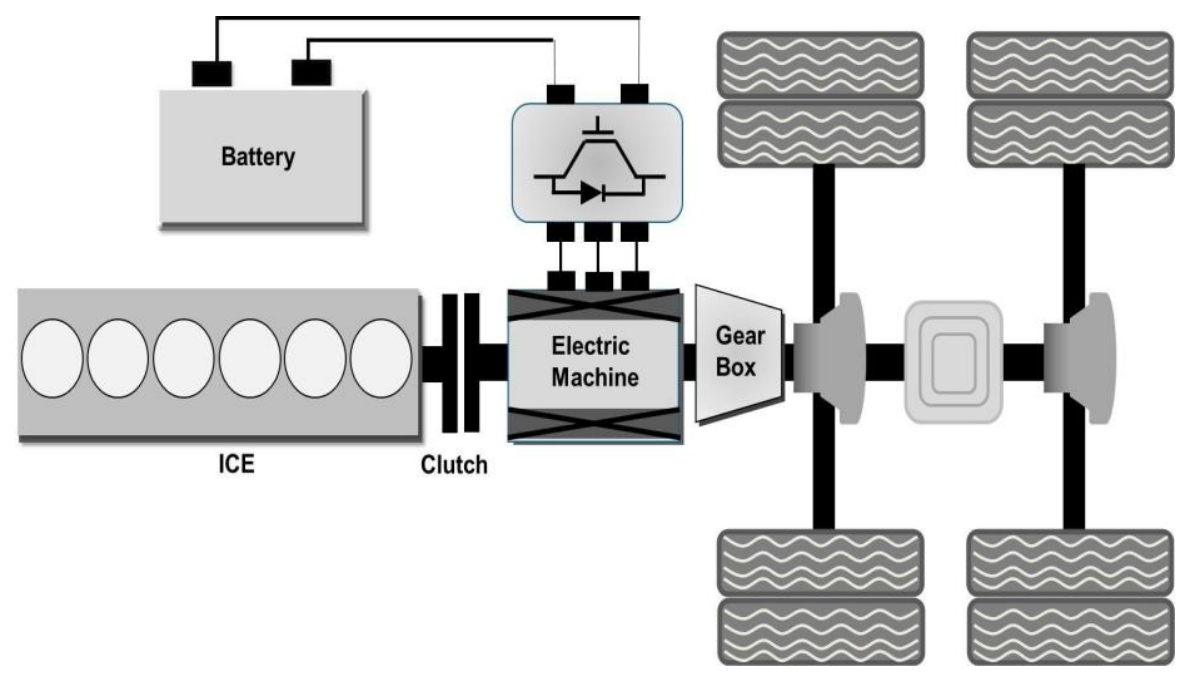

Fig. 5. Configuration of the hybrid driving train.

The model is established in two models of operation. In the city, the truck only operates with a battery to meet the restriction of transportation electrification. On the highway, the energy is completely supported by the ICE, which can provide enough power for traveling for $300 \mathrm{~km}$. The speed of these two methods is shown in Figures 6 and 7 . When the CNG is pumped into the ICE, the pressure is then lowered to the point compliant with the engine. After that, the air-fuel mixture will be ignited to generate power and to push the truck. 


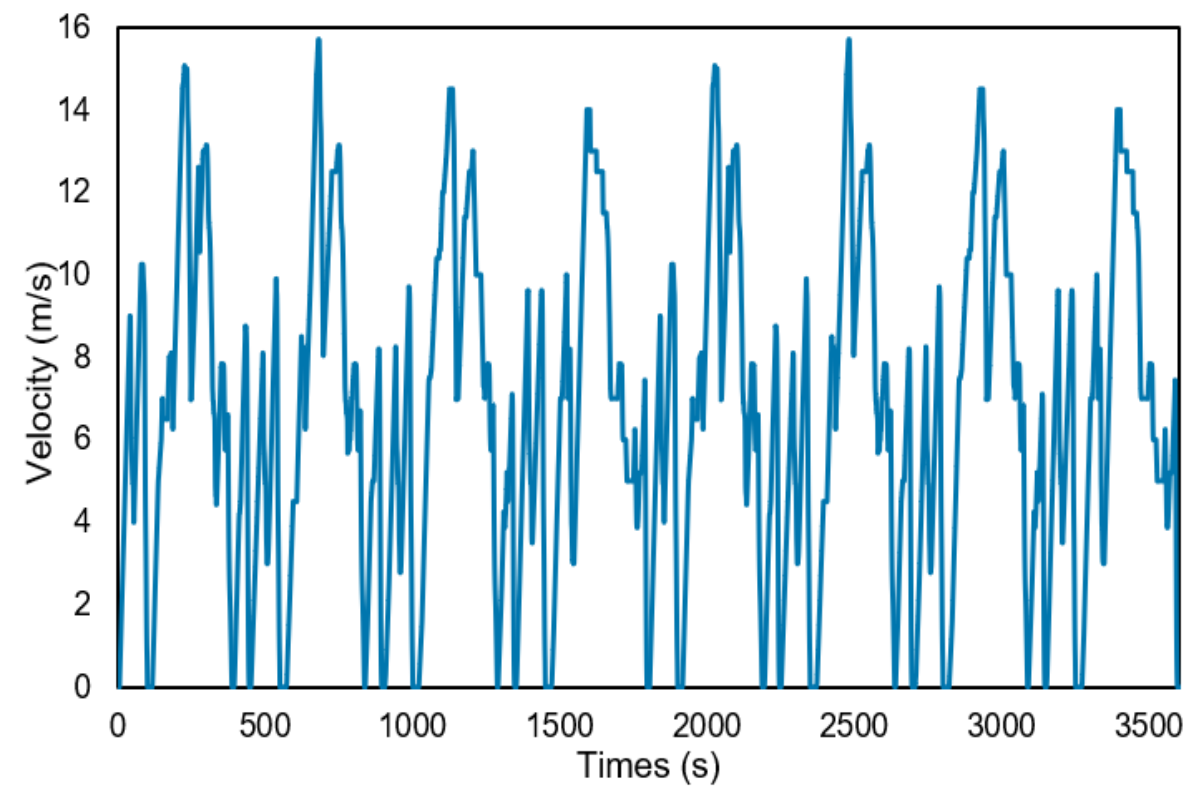

Fig. 6. Real-world city road driving cycle (24km).

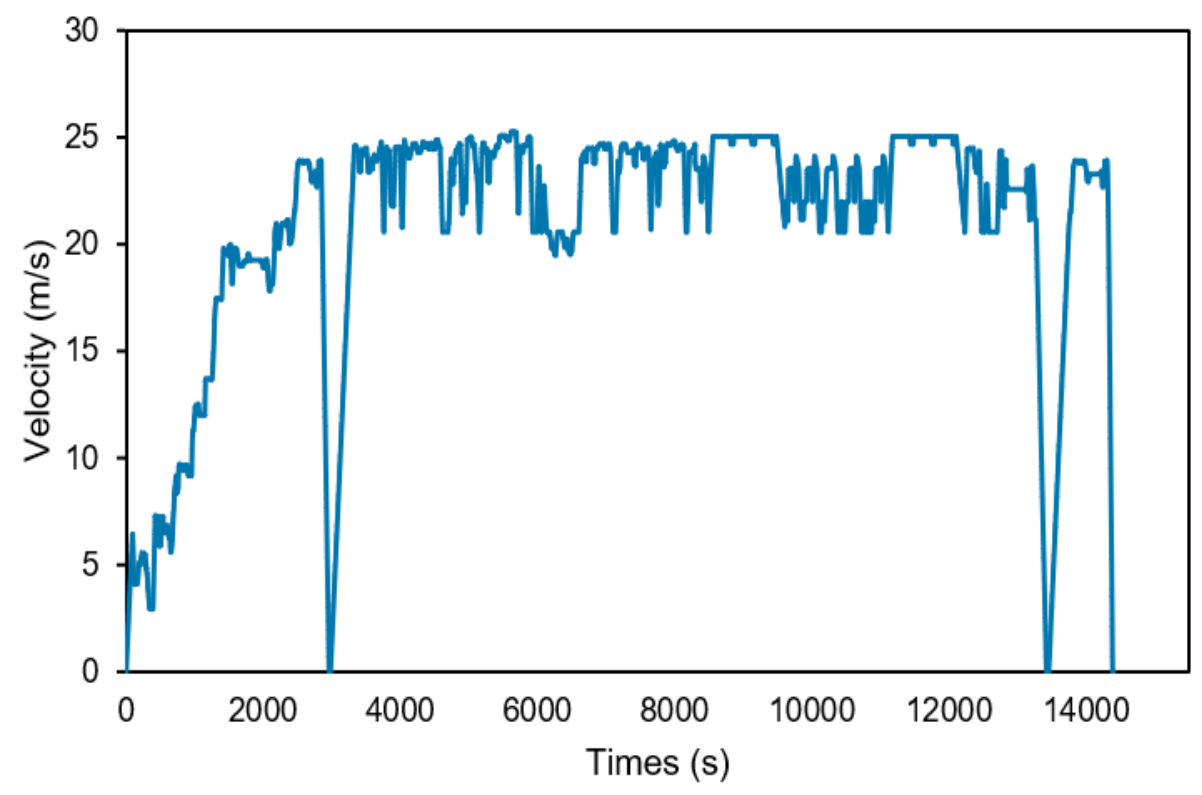

Fig. 7. Real-world highway driving cycle (300km).

In terms of cost savings and maximum energy efficiency, the optimum power of the battery is determined based on 5 different city-running cycles. The state of charging (SOC) is the key value to illustrate the battery charge state, which is important for the longdistance running and charging strategy. It refers to the current power contained in the battery, $100 \%$ equal to fully charged, while $0 \%$ means that the battery is completely discharged. The change in battery capacity is studied in areal city cycle, with battery starting with $80 \%$ electricity and $30 \%$ at the end. 


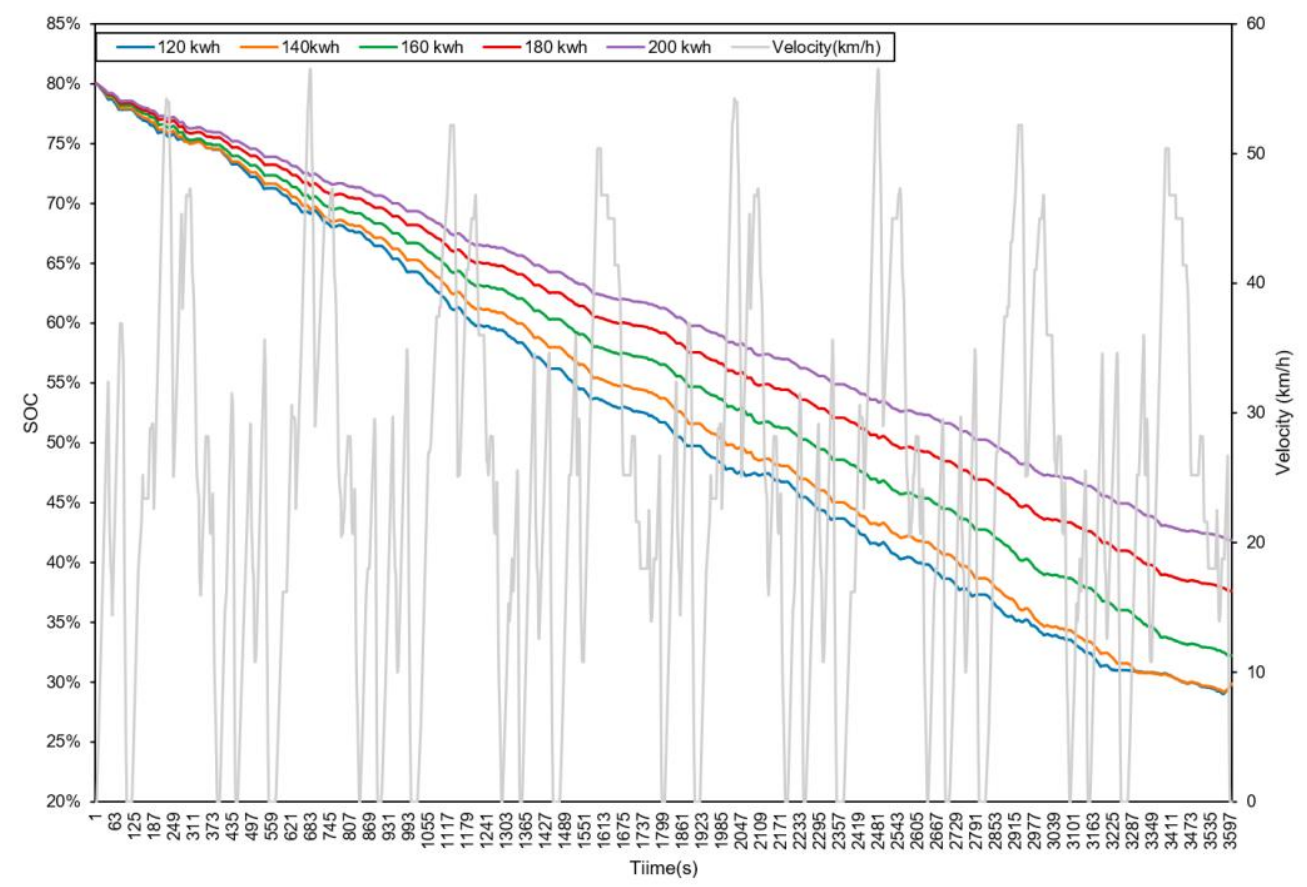

Fig. 8. SOC vs. battery capacity variation.

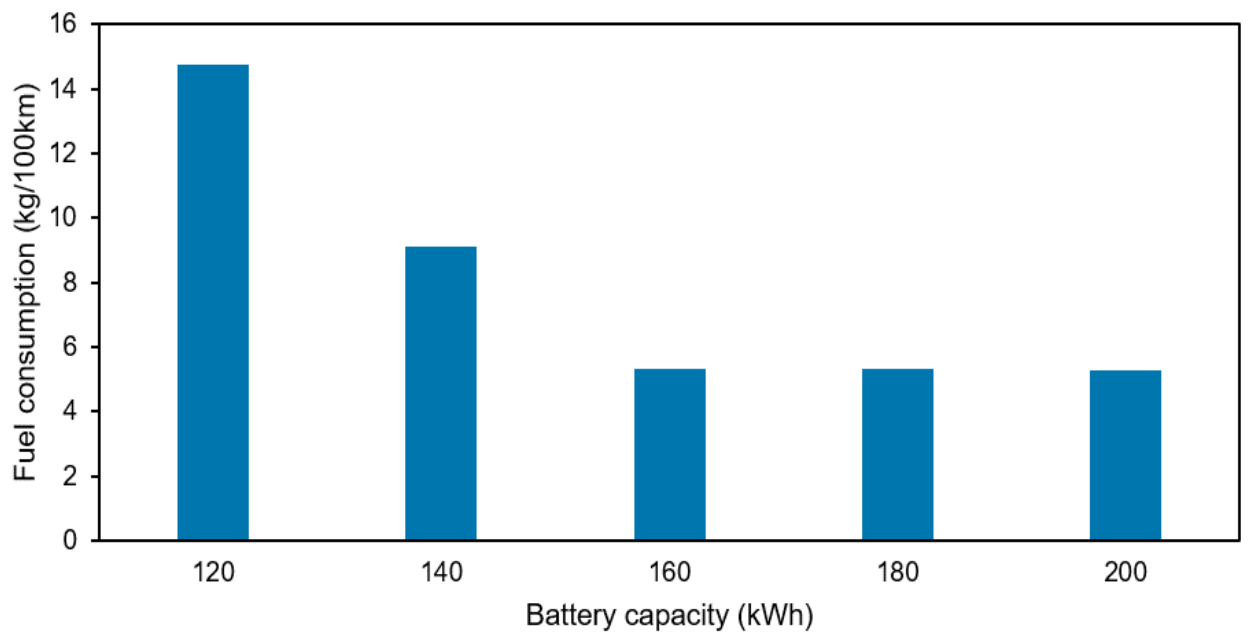

Fig. 9. Fuel consumption with different battery capacities when running in the city $(\mathrm{kg} / \mathrm{kWh})$.

The battery is set with different capacities from 120 to $200 \mathrm{kWh}$. For a $200 \mathrm{kWh}$ battery, there still are $42 \%$ of power remaining at the end, while a $120 \mathrm{kWh}$ battery is not enough to provide kinetic energy to complete $24 \mathrm{~km}$ long fully electric driving. Considering the truck' total weight and $50 \%$ of the battery energy availability, a $160 \mathrm{kWh}$ battery is selected through the simulation. The battery weight is taken into account as a ratio of $13.8 \mathrm{~kg} / \mathrm{kWh}$ [3].

When the truck is driving at a high speed, the ICE is used to provide energy. Compared with diesel trucks, the CNG-based truck has good fuel consumption and $\mathrm{CO} 2$ emissions 
with high heating value. For $25 \mathrm{t}$ load weight truck, this can save $15.84 \%$ of energy, and this advantage will become even more obvious for heavy trucks, as shown in Figure10.

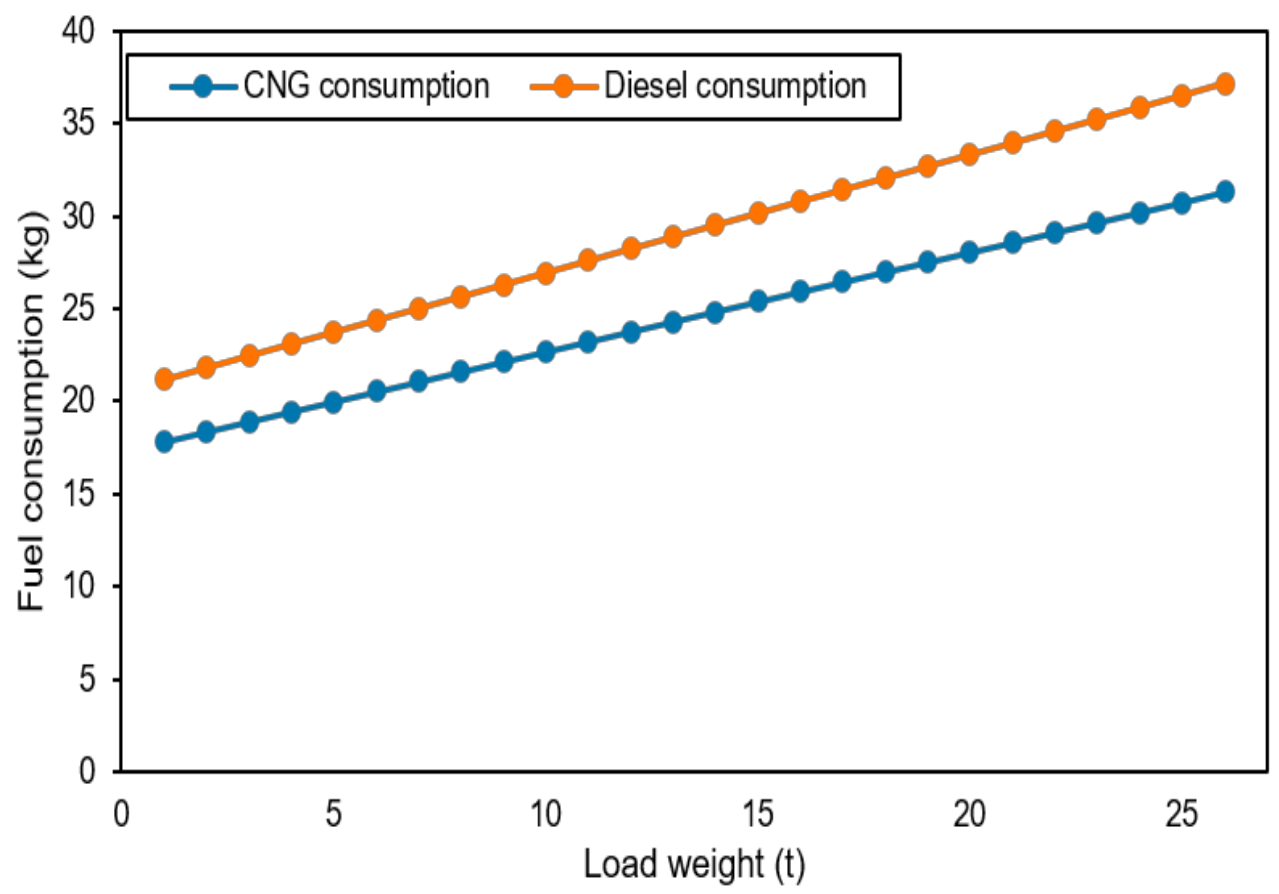

Fig. 10. Tank-to-Wheel fuel consumption for $\mathrm{CNG}$ and diesel-based hybrid electric truck.

$\mathrm{CO} 2$ is emitted directly into the atmosphere after the complete combustion of NG in this process. For a heavy hybrid electric truck carrying a $25 \mathrm{t}$ load, $84.43 \mathrm{~kg}$ of $\mathrm{CO} 2$ are emitted for every $100 \mathrm{~km}$ run. The $\mathrm{CO} 2$ emissions in this process account for $71.4 \%$ of the entire life cycle.

Methane slippage or unoxidized methane emissions usually occur due to low catalyst temperatures of at lower loading and transient driving cycles. For hybrid electric trucks, methane emissions from $\mathrm{TtW}$ assumed to be at $0.6 \%$, while for diesel-based trucks, methane slippage amounts to $0.0093 \mathrm{~g} / \mathrm{km}$ [10]. Therefore, minimization of unburned methane slippage from the engine may help to achieve emission reduction. Methane emissions continue to increase as the amount of fuel consumed increases. Since the tailpipe methane emissions vary depending on the engine type and fuel injection, taking advanced technology maybe a good way to reduce methane emissions. 


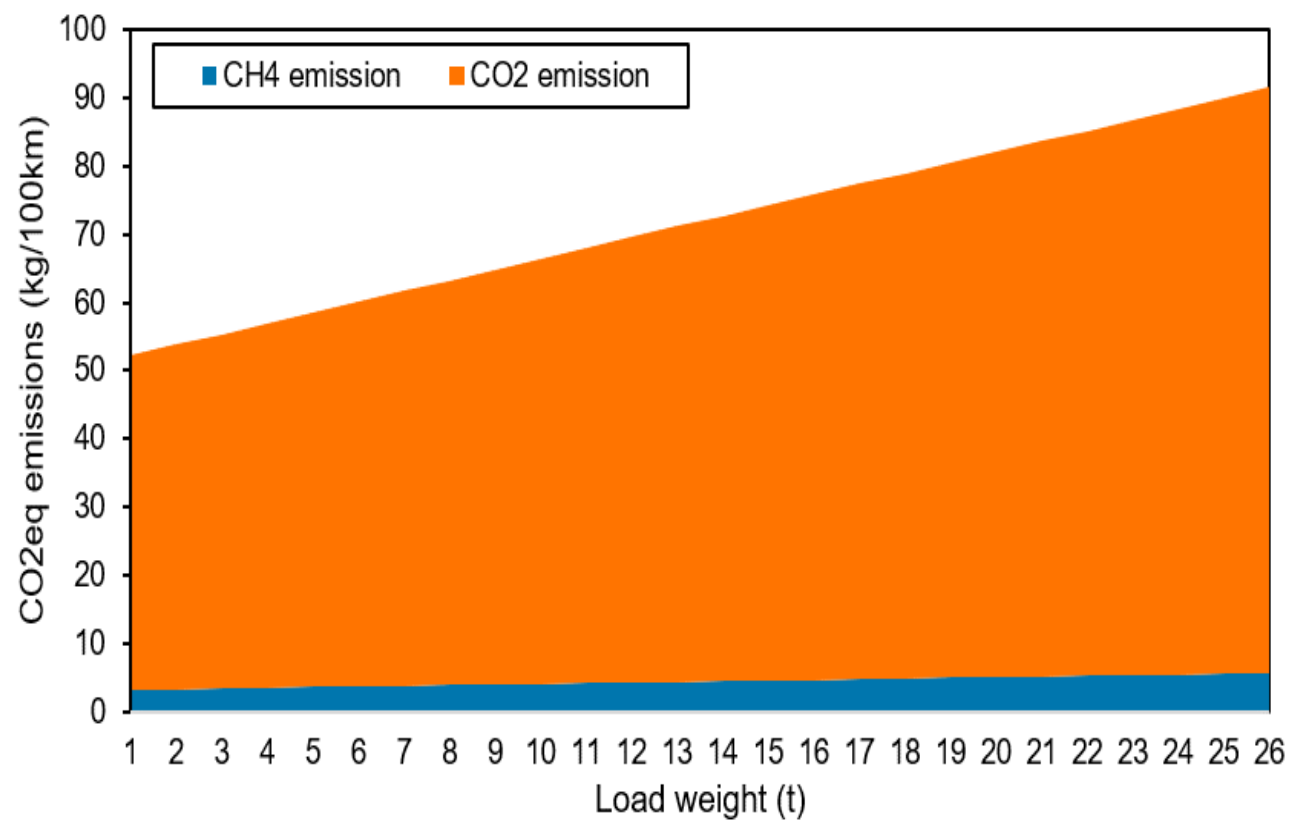

Fig. 11. Tank-to-Wheel CO2equivalent emissions vs. varying load weights.

\section{WELL-TO-WHEEL ANALYSIS}

Summarizing the WtW process, $\mathrm{CO} 2$ is the largest source of gas emissions, account tin for more than $97 \%$, while about $2 \%$ of gas emissions come from methane emissions. The remaining gases, such as $\mathrm{N} 2 \mathrm{O}, \mathrm{NOx}, \mathrm{SOx}, \mathrm{PM} 10$, etc., constitute less than $1 \%$ and are not studied here. Although the $\mathrm{CH} 4$ emissions proportion is not very high, it still has a great importance for a deep study due to its huge impact on GHG emissions.

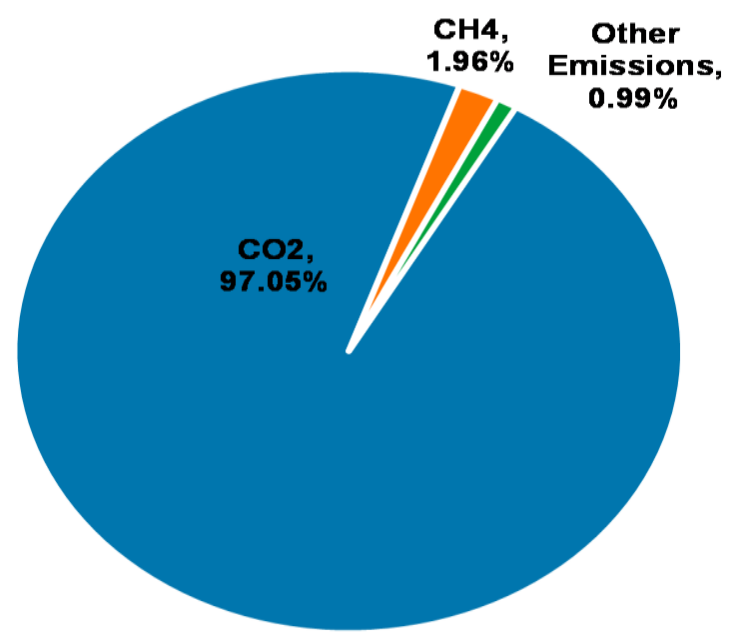

Fig. 12. Well-to-Wheel gas emissions proportion. 
Based on the analysis in Section 3 and Section 4, the benefits of using CNG as a fuel depend on minimizing $\mathrm{CH} 4$ leakages and slippage during the entire fuel pathway. Combining the results of $\mathrm{WtT}$ and $\mathrm{TtW}$, the $\mathrm{CO} 2$ equivalent emissions for the whole life cyclecan be obtained.

The major contribution of $\mathrm{CO} 2$ emissions can be derived from the combustion of $\mathrm{CNG}$ during the driving cycle, and the emissions are quite different depending of the load weight. For heavy trucks, they consume a huge amount of fuel, and the primary energy required in the WtT process generates more $\mathrm{CO} 2$ per unit of fuel. The contribution of each stage to GHGs can be better seen in Figure 13.

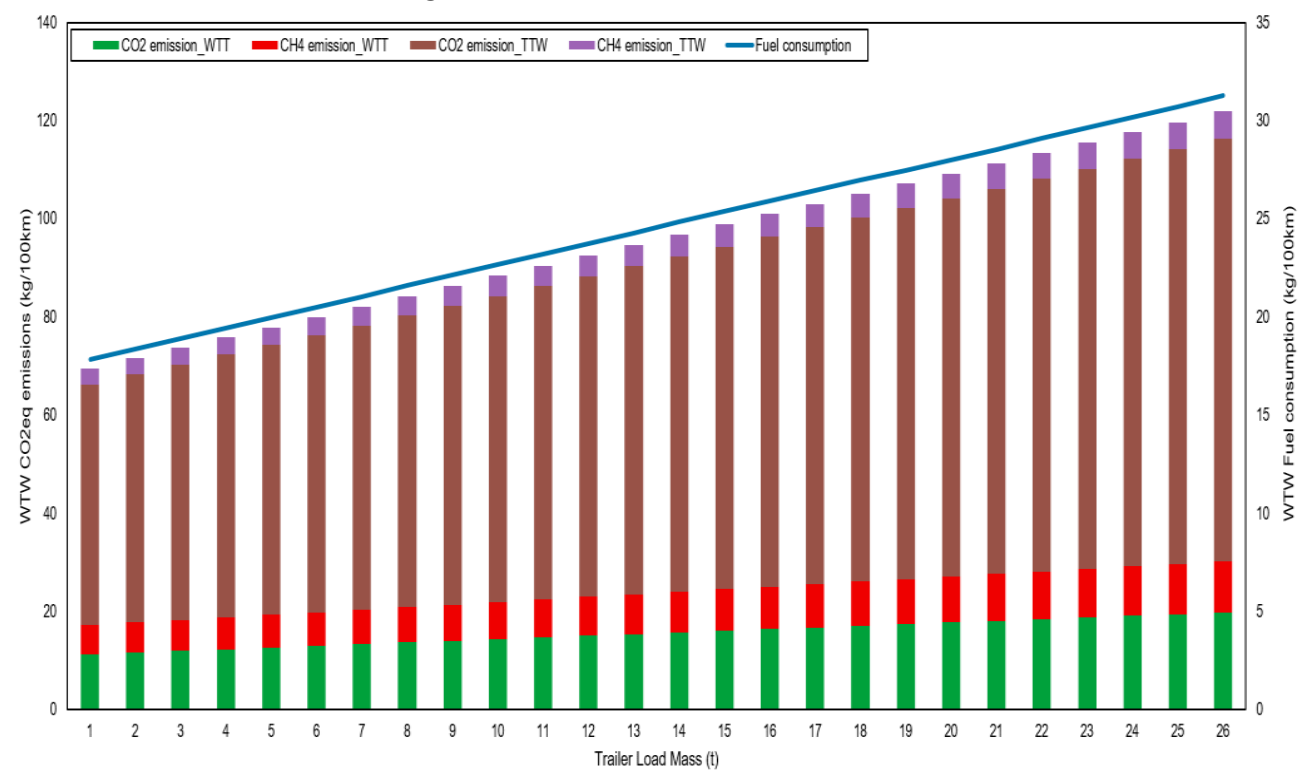

Fig. 13. Well-to-Wheel CO2equivalent emissions and CNG consumption.

Excluding $\mathrm{CO} 2$ emissions from the $\mathrm{NG}$ combustion in an engine, most of the $\mathrm{CO} 2$ equivalent emissions come from the WtT stage, which is mainly caused by methane emissions generated in the recovery process and $\mathrm{CO} 2$ emissions during the compression process. With an increase in truckload weight, the impact of this kind of leakages and emissions will become more severe.

Compared with diesel-based hybrid electric trucks, CNG-based trucks have much lower level of $\mathrm{CO} 2$ emissions during operation, about $81 \%$ of the amount for diesel-based trucks. However, that difference is not as obvious as $\mathrm{TtW}$ in the WtT process. In general, the application of $\mathrm{CNG}$ in hybrid electric trucks is still environmentally friendlier than the diesel ones in the whole fuel value chain, especially for the heavy-duty trucks. If appropriate measures can be taken to reduce methane leakages and emissions, the role of applying the CNG in hybrid electric trucks will be more significant. In addition, it will be more helpful to achieve emissions standards as soon as possible. 


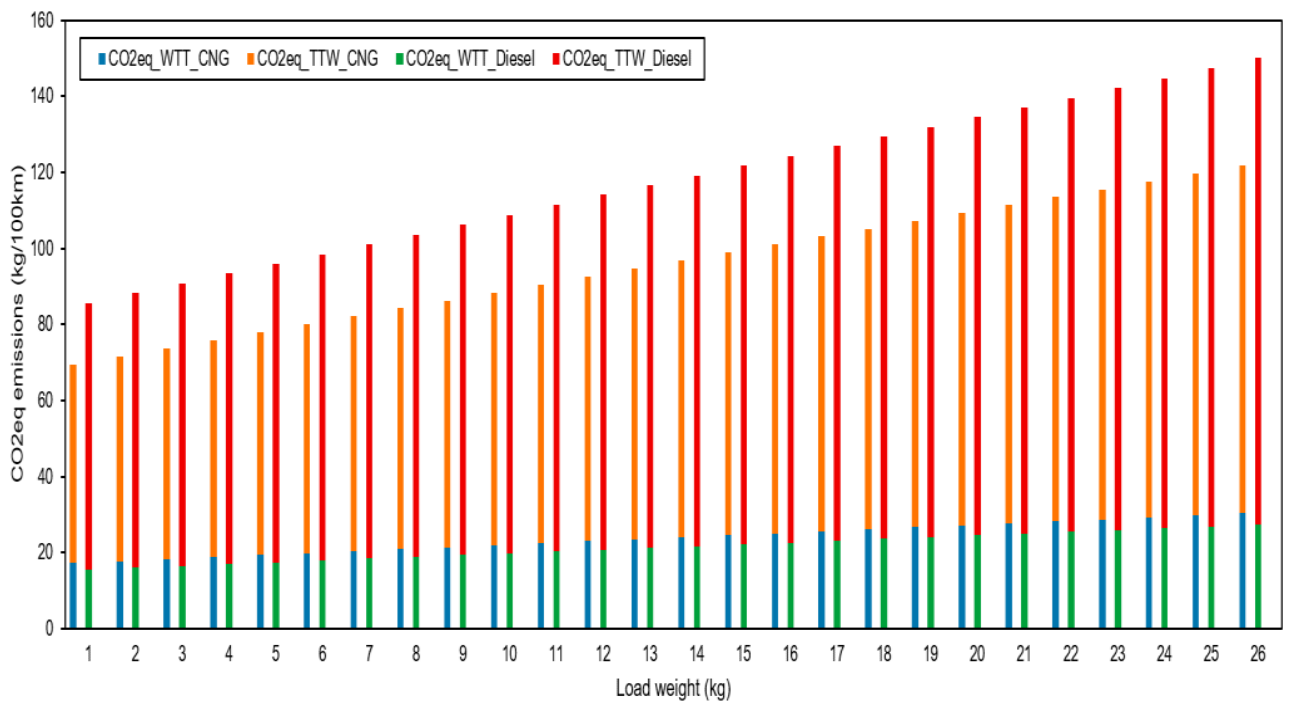

Fig. 14. Well-to-Wheel CO2 equivalent emissions comparison between $\mathrm{CNG}$ and diesel.

\section{Summary}

The total $\mathrm{CO} 2$ equivalent emissions from different sectors are showed in this bar graph; the left part is composed of $\mathrm{CO} 2$ emissions and the right part is caused by methane emissions (15.5\% of CO2 equivalent). Specifically, methane leakages have high rates, which has a huge influence on $\mathrm{CO} 2$ emissions reductions. For North America, the most CO2eq coming from the recovery process is due to the high rate of methane emissions.

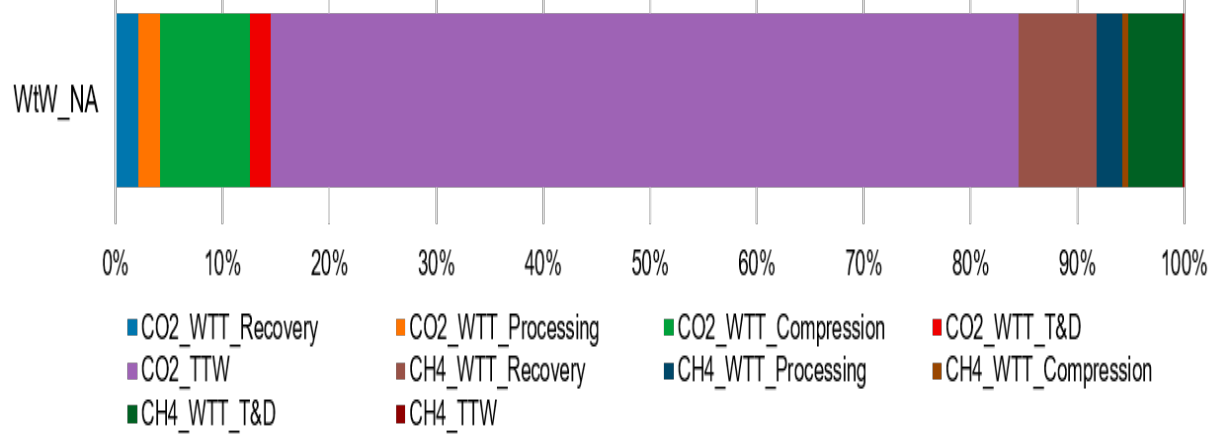

Fig.15. Summary of Well-to-Wheel CO2 equivalent emissions in each part.

Reducing upstream methane leakages will be a key for the determination of the positive or negative climate benefits of applying the CNG in hybrid electric trucks. The improved equipment and advanced detecting apparatus can help to repair methane leaks and reduce their amount. Meanwhile, improving compressor efficiency to reduce energy costs is another factor to look out for. From the prospects of policy support, publishing new regional standards requiring the capture of gas during well completion and from tanks may be a good way to achieve this objective.

This study provides a detailed evaluation of the hybrid electric trucks for applying WtW method for the CNG and diesel. The heavy-duty hybrid electric trucks have a great potential to reduce $\mathrm{CO} 2$ emissions. This benefit is apparent with the increase in load 
weights. CNG-based hybrid electric trucks may achieve better performance as compared to diesel ones in terms of GHG emissions. However, methane emissions during the fuel production and truck operation stages can negate this advantage. The emission of $\mathrm{CH} 4$ throughout its life cycle is affected by many factors, and methane leakages in the recovery stage bring a large increase in $\mathrm{CO} 2$ equivalent emissions for the entire lifecycle. Using new technologies and innovations may help to capture and sequester the methane vented during gas production and treatment. Besides, improving energy efficiency is the key to significantly reduce carbon emissions, especially in the process of compression.

This study uses a comprehensive method to study the specific emissions at each WtW stage of CNG-based hybrid electric trucks. The results of this analysis can be used as a guide for the strategic decision-making of future energy transportation policies to better understand the trade-offs between energy and the environment. Also, it can help identify environmental opportunity in developing the transportation industry.

Even though hybrid electric trucks have strong potential to mitigate carbon pollution, the numerous countries' strategies may also impact their future promotion and adoption. This article focuses on greenhouse gas pollution, and does not perform a thorough analysis of different hybrid electric truck powertrains. Optimizing the configuration and powertrain efficiency could be another potential way to conserve energy and reduce pollution, which would be a good point to be explored in future studies. Other advantages of natural gas fuel, such as significant economic benefits and the cost of the total infrastructure, are also beyond the reach of this work. Further researches based on these areas of studies may also have lots of interesting results.

\section{Reference}

1. I. E. Agency. CO2 Emissions from Fuel Combustion (2018).

2. C. C. Ambel. Too big to ignore - truck CO2 emissions in 2030 (2015).

3. B. Nader, W. S., C. J. Mansour, M. G. Nemer and O. M. Guezet . Proceedings of the institution of mechanical engineers, Part D: journal of a tomobile engineering Exergo technological explicit methodology for gas-turbine system optimization of series hybrid electric vehicles. 232(10), 1323-1338 (2018).

4. J. Bradbury, Z. Clement, A. Down . Office of Energy Policy and Systems Analysis Greenhouse gas emissions and fuel use within the natural gas supply chain-Sankey Diagram Methodology. United States Department of Energy, Washington, DC. (2015).

5. L. Capuano. International energy outlook. US Energy Information (2018).

6. Administration (EIA): Washington, DC, USA (2018).

7. S. Chambliss, J. Miller, C. Façanha, R. Minjares, K. Blumberg . The International Council on Clean Transportation The impact of stringent fuel and vehicle standards on premature mortality and emissions (2013).

8. Commission. Full fuel cycle assessment well to tank energy inputs, emissions, and water impacts, Cupertino (2007).

9. C. E. Commission. Alternative Fuels Expert Group Report (2017).

10. A. Delgado, R. Muncrief .Assessment of heavy-duty natural gas vehicle emissions: implications and policy recommendations. International Council on Clean Transportation: Washington, USA. 1-42 (2015). 
11. A. Demirbas. Energy sources Bioenergy, global warming, and environmental impacts 26(3), 225-236 (2004).

12. U. EPA. Fast facts on transportation greenhouse gas emissions (2020).

13. R. S. Kraus. Petroleum refining process (2013).

14. R. Lindsey. Climate news, stories, images, \& video (Climate Watch Magazine).

15. V. Litvinenko. Resources The Role of Hydrocarbons in the Global Energy Agenda: The Focus on Liquefied Natural Gas. 9(5), 59 (2020).

16. M. J. Nahlik, A. T. Kaehr, M. V. Chester, A. Horvath and M. N. Taptich . Journal of Industrial Ecology Goods movement life cycle assessment for greenhouse gas reduction goals. 20(2), 317-328 (2016).

17. J. Sihvonen. CNG and LNG for vehicles and ships - the facts (2018).

18. A. Thiruvengadam, M. Besch, D. Carder, A. Oshinuga, R. Pasek, H. Hogo and M. Gautam . Journal of the Air \& Waste Management Association Unregulated greenhouse gas and ammonia emissions from current technology heavy-duty vehicles66(11), 1045-1060 (2016). 